\title{
Europa, entre las reglas y el poder
}

\author{
Hans Kribbe: The Strongmen: European Encounters \\ with Sovereign Power. McGill-Queen's University Press, \\ Montreal, 2020, 239 pp.
}

\section{J. Martín Ramírez y Jerzy Biziewski (eds.): Security and Defence in Europe. Springer, Cham, 2020, 264 pp.}

\section{Fernando Delage \\ Universidad Loyola Andalucía}

En 2020, no mucho después de que la crisis del euro, el drama de los refugiados y el terremoto del Brexit situaran a la Unión Europea ante el momento más crítico de su historia, la Declaración Schuman cumplió 70 años. El proyecto de integración pudo celebrar el aniversario demostrando su fortaleza, y confirmando -como ya había anticipado su principal arquitecto, Jean Monnet-, que Europa sólo se forjaría sobre la base de sucesivas crisis. La conmemoración ha coincidido, no obstante, con uno de esos procesos históricos que marcan el comienzo de una nueva era: la quiebra del orden internacional construido tras la Segunda Guerra Mundial, sin el cual no existiría la UE. Europa se asoma hoy a un mundo incierto y fragmentado, cuyos retos empequeñecen las dificultades que ha atravesado desde la crisis financiera de 2008. La redistribución en curso del poder global disminuye, por un lado, su peso internacional. Su concepción de un orden basado en el Derecho y la democracia choca, por otro, con la irrupción de unas potencias autoritarias para las que no existe más lenguaje que el del poder. La fluidez geopolítica de un mundo en transición, que obstaculizará la defensa de los intereses y valores europeos, demanda algo más que un mero reajuste a las nuevas realidades.

\section{Pérdida de peso global}

En 1970, los Estados que hoy forman la UE representaban el 38 por cien del PIB global. En 2018 (todavía con 28 Estados miembros), esa cifra había caído en torno al 25 por cien, similar a la proporción de Estados Unidos, y por encima del 18 por cien de China (cuyo PIB equivalía en 1970 a sólo 
el 0,8 por cien de la economía mundial). Según algunas estimaciones, el porcentaje de la UE de 27 será del nueve por cien en 2050. Los indicadores demográficos tampoco son muy alentadores: pese a contar con 500 millones de habitantes (un 50 por cien más que Estados Unidos, tres veces más que Rusia y menos de la mitad de China), Europa es el único continente en el que las Naciones Unidas prevén una caída de la población entre 2010 y 2060 , con una reducción del 4,9 por cien. Una de sus consecuencias es el rápido envejecimiento de las sociedades europeas: los mayores de 65 años, que sumaban el ocho por cien en 1950, representan el 16 por cien en la actualidad, y podrán llegar al 27 por cien en 2050. Nunca habrá sido más apropiado hablar del "Viejo" Continente.

La evolución hacia un sistema multipolar es otro factor que condiciona su posición en la jerarquía internacional. Durante la Guerra Fría, los europeos tuvieron que acostumbrarse a vivir entre Estados Unidos y la Unión Soviética. Aunque la confrontación entre Washington y Moscú se extendió a todo el planeta, Europa era el espacio que se encontraba en el centro de la competición entre ellas. Desde 1991 Europa no está dividida en dos bloques, pero el destino del mundo ya no depende de su control. El viento de la Historia ha dejado de soplar de Oriente a Occidente, como pensaba Hegel, para regresar desde este último hacia Asia, donde la rivalidad entre Estados Unidos y China será la variable fundamental que determinará el orden mundial sucesor del establecido en 1945.

Las repercusiones de la transformación del equilibrio de poder son enormes para Europa. El proceso de integración nació para dejar atrás las guerras y los totalitarismos, mediante una estructura supranacional que ha proporcionado la unidad, la seguridad y la prosperidad que necesitaba el continente. Conforme a un modelo sin precedente en la historia política, los Estados miembros optaron por resolver sus diferencias a través de normas e instituciones comunes. Pero la convicción de que esa manera de hacer las cosas sería emulada por otras naciones a medida que se desarrollaran sus economías y se modernizaran sus sociedades, ha resultado errónea. Ciertas potencias emergentes, con ideas propias sobre cómo organizar el sistema internacional, rechazan la idea de que su comportamiento tenga que estar sujeto a unas supuestas reglas universales (como también creen por cierto algunos de los Estados de más reciente incorporación a la Unión). Este nuevo pluralismo no sólo ha frustrado las expectativas de la UE, sino que la sitúa ante un escenario radicalmente diferente del que ha conocido durante sus primeras siete décadas ("After Europe", lo denominó Ivan Krastev)1. El modo de pensar Europa debe cambiar en consecuencia, si se quiere hacer frente a un doble desafío: el intelectual de comprender las causas e implicaciones de la ruptura del orden

${ }^{1}$ Ivan Krastev, After Europe. University of Pennsylvania Press, Filadelfia, 2017.

Araucaria. Revista Iberoamericana de Filosofia, Política, Humanidades y Relaciones Internacionales, año $23, \mathrm{n}^{\circ} 48$. Tercer cuatrimestre de 2021. Pp. 631-636. ISSN 1575-6823 e-ISSN 2340-2199 https://dx.doi.org/10.12795/araucaria.2021.i48.29 
internacional liberal; y el práctico de formular una estrategia eficaz en defensa de sus prioridades.

Como ha señalado el Alto Representante para Asuntos Exteriores y Política de Seguridad Común, Josep Borrell, para avanzar en esa dirección Europa tendría que cerrar la brecha entre sus capacidades económicas (más que notables) y su influencia geopolítica (casi inexistente). Naturalmente, hacer de una Unión concebida como potencia civil y normativa un actor estratégico es un reto mayúsculo, para el que se carece de los instrumentos y -requisito previo- de la voluntad de todos los Estados miembros. Pero recuérdese que fueron las amenazas externas - las divisiones de Stalin-, además de la devastación económica de la guerra y la experiencia del fascismo y el comunismo, las que hicieron posible la fundación del proyecto europeo. A comienzos de la tercera década del siglo XXI, el mundo exterior - la debacle en Afganistán ha sido el ejemplo más reciente- ha vuelto a llamar a las puertas de Bruselas: la respuesta (o falta de ella) delimitará el juicio de los historiadores del futuro sobre los líderes europeos.

\section{Un debate necesario}

No es éste un debate que parezca atraer como merece la atención de la opinión pública, pero sí del mundo académico. Proliferan las publicaciones sobre el futuro de Europa, entre las que cabe incluir el reciente monográfico de Araucaria (número 45), o los dos libros objeto de esta reseña. El primero de ellos presta atención a los (limitados) avances en la política exterior y de defensa común, y a los problemas más inmediatos de seguridad que afronta la UE. El segundo analiza la interacción de los europeos con una serie de líderes autoritarios, unidos tanto por sus ambiciones revisionistas del orden internacional como por una manera de entender la política que está en las antípodas de las prácticas bruselenses.

Security and Defence in Europe, editado por J. Martín Ramírez y Jerzy Biziewski (profesor en la Universidad Nebrija, y general retirado polaco, respectivamente), es un libro desconcertante. Es frecuente que muchas obras colectivas tengan su origen en conferencias científicas y sean, por tanto, irregulares en cuanto a su calidad y contenido. En este caso parece tratarse directamente de unas actas de congreso, buena parte de ellas sin pulir para su publicación. Se menciona que se trata de las contribuciones a la "XLV CICA" (sic), sin aclararse ni el significado de las siglas (no hay índice de abreviaturas) ni el lugar de celebración. La heterogeneidad no puede ser mayor entre los 18 capítulos, tampoco numerados, que firman autores de hasta nueve países distintos. Debe ser un nuevo ejemplo de ese publish or perish del mundo académico, que en ocasiones termina convirtiendo al medio en el fin. 
Aunque resulta difícil sintetizar unas ideas comunes a textos tan diversos, con temas en casi todos los casos esbozados más que desarrollados (son capítulos de muy escasas páginas), entre aportaciones que aquí resultan incomprensibles (como la lucha contra la corrupción en Noruega o el cambio climático en el Ártico), otras identifican al menos aquellos asuntos coherentes con el título del libro. Se recuerda la fallida historia de la Comunidad Europea de Defensa, se examina el nuevo mecanismo de Cooperación Estructurada Permanente (PESCO), y se pasa revista a problemas transnacionales como la emigración, la ciberseguridad, o la no proliferación. Con un enfoque algo más sistemático en la segunda mitad del libro, la Parte III examina los frentes septentrional, oriental y meridional de la seguridad europea, mientras que la Parte IV se centra en el análisis de la relación entre la UE y la OTAN, y en el dilema que plantea a esta última -y por tanto a Estados Unidos- la discusión sobre la independencia estratégica europea. Ésta es, en último término, la cuestión que sirve de hilo conductor -más implícito que explícito- a este conjunto de contribuciones, como también subraya la exministra de Asuntos Exteriores Ana Palacio en su breve prólogo 2 .

El reto de situarse en el mundo que viene es el objeto del segundo libro que nos ocupa, The Strongmen: European Encounters with Sovereign Power; un fascinante estudio sobre las dificultades europeas para comprender un entorno internacional en el que operan personajes como Recep Tayyip Erdogan, Vladimir Putin, Xi Jinping y, hasta el año pasado, Donald Trump. Su autor, Hans Kribbe, doctor en Teoría Política, antiguo asesor en la Comisión Europea y posteriormente en el gabinete de comunicación del Kremlin, ha escrito en realidad dos obras en una. En la primera disecciona lo que tienen en común estos líderes (perfectamente extensible a otros como Duterte, Bolsonaro o Lukashenko). En la segunda estudia el "encuentro" de Bruselas con cada uno de ellos durante los últimos años.

Partiendo de la premisa de que, pese a sus respectivas singularidades, estos "hombres fuertes" (los strongmen del título) comparten una misma aproximación a la vida política, Kribbe se apoya en la tipología de Alexandre Kojève sobre los diferentes modelos de proyección del poder -el Padre, el Amo, el Líder y el Juez- para examinar a los cuatro dirigentes mencionados. Las breves líneas de una recensión no pueden hacer justicia a la brillante combinación de análisis conceptual y reveladoras anécdotas con la que el autor observa a estas figuras. Lo relevante a nuestros efectos es que comparten una filosofía política que no puede estar más alejada de los patrones europeos: cualquier medio les resulta legítimo para imponer su voluntad. Su poder no se apoya en instituciones como

\footnotetext{
2 Sobre el mismo asunto, véanse los recientes trabajos de Luuk van Middelaar, "Europe's geopolitical awakening", Groupe d'Études Géopolitiques, Working Paper 8, abril 2021; y Nathalie Tocci, "European Strategic Autonomy: What It Is, Why We Need It, How to Achieve It", Istituto Affari Internazionali, 2021.
} 
parlamentos o tribunales, sino en redes personales, en maniobras opacas, en el recurso a la coerción y la manipulación informativa. El choque con unos actores que nunca aceptarán las reglas que han definido la razón de ser de la UE ha supuesto un duro despertar, agravado por el imperativo de tener que entenderse con ellos.

Ucrania fue una de las primeras indicaciones. La Comisión Europea negociaba la adopción por Kiev de directivas y reglamentos con vistas a su adhesión, sin ser consciente al parecer de sus efectos geopolíticos y de la previsible reacción rusa. Un proceso que se pensaba burocrático acabó en una guerra, en violación de los pactos con que se puso fin a la Guerra Fría. Por mucho que se demonizara a Putin, para quien los valores que representa la UE constituyen una amenaza existencial a su régimen, la conclusión del conflicto exigió llegar a un acuerdo con Moscú. ¿Qué decir de Erdogan? De su supresión del kemalismo y la democracia, o de sus ambiciones de reconfiguración del Mediterráneo Oriental. La crisis de los refugiados condujo a Bruselas a ponerse en sus manos, regalándole un instrumento de chantaje que le ha permitido, incluso, insultar públicamente a la presidenta de la Comisión. Xi Jinping, mientras redobla la represión interna, no oculta su ambición de situar a China al frente de una nueva fase de la globalización, desplazando a las democracias occidentales del centro de la economía mundial. Con todo, ninguna sorpresa fue mayor que la elección, en 2016, de Donald Trump, un presidente norteamericano que definió a la UE como enemigo ("es como China, pero más pequeña", llegó a decir) y obligaba a abandonar definitivamente la idea de que los valores liberales se extenderían gradualmente al conjunto del planeta. Como declaró poco después la canciller alemana, Angela Merkel, "los europeos tendremos que tomar el destino en nuestras propias manos". Europa había entrado ciertamente en un mundo gobernado por otras prácticas y principios.

\section{Los límites de un modelo}

"Soberanía europea", "autonomía estratégica", son los términos que definen el debate. Al tomar posesión como presidenta, Ursula von der Leyen calificó a su Comisión como una "Comisión geopolítica", a la vez que Borrell urgió por su parte a aprender "el lenguaje del poder". Pero cómo pretende la UE acometer tal metamorfosis dista de estar claro. No se trata tanto de adquirir nuevos instrumentos y capacidades, cuanto de aprender a razonar y a actuar como una gran potencia, en un terreno -y con una gramática- hasta ahora desconocidos para ella. Sin renunciar a la defensa de sus valores, Europa debe reconocer que éstos no son compartidos de manera universal; que compite con otros poderosos 
actores por su seguridad, prosperidad e influencia; y que necesita, en definitiva, asumir un nuevo concepto de su papel en el mundo. Como señaló hace unos años el exministro alemán de Asuntos Exteriores, Sigmar Gabriel, "en un mundo lleno de carnívoros, los vegetarianos lo pasan mal".

En efecto, mientras Europa todavía intenta gestionar su proyección internacional de conformidad con sus reglas, la experiencia con este tipo de líderes y con la creciente complejidad global ha revelado su ineficacia. Putin puede permitirse hacer caso omiso de las sanciones occidentales, mientras no ceja en su empeño de debilitar el proyecto europeo y la estabilidad de las democracias mediante las técnicas híbridas del sharp power. Erdogan ya no necesita ni quiere ser miembro de la UE; por el contrario, utiliza las críticas de Bruselas para consolidar el apoyo interno de su opinión pública. Xi dirige un gigante económico y tecnológico sobre la base de unos valores incompatibles con los de los europeos, aunque éstos no pueden prescindir del acceso a una nación que representa a la quinta parte de la humanidad y será pronto la mayor economía del planeta. Trump se fue, pero el trumpismo no. Incluso con Biden -Afganistán ha vuelto a demostrarlo-, la relación transatlántica difícilmente volverá a ser la que fue.

La UE requiere pues, según Kribbe, la capacidad de moverse simultáneamente en varios terrenos de juego; la agilidad mental para poder operar con el lenguaje de las reglas y el lenguaje del poder. Después de todo, como ya indicó Maquiavelo, actuar políticamente significa afrontar la tensión entre lo ideal y lo posible, entre lo correcto y lo necesario. No se trata sólo de proponer las mejores soluciones, sino también de maximizar opciones, crear nuevas oportunidades y superar los innumerables obstáculos que surgirán en el camino.

De manera provocadora, el libro encuentra en su conclusión ciertas semejanzas entre la Europa de hoy y la China imperial del siglo XIX. Convencida de la superioridad de su cultura, la clase dirigente china respondió al ascenso de Europa con arrogancia y desprecio. Encerrada en sí misma y paralizada por la excepcionalidad de su identidad, fue incapaz de adaptarse a las fuerzas de cambio desatadas por la Revolución Industrial (como sí supo hacer Japón) ${ }^{3}$. Sólo a partir de las guerras del Opio se dio cuenta Pekín de su extrema vulnerabilidad y de lo insostenible de su modelo. Tuvo que sufrir una humillación tras otra para aceptar que su sofisticación cultural no era garantía de independencia. Si Europa se aferra desesperadamente a la idea de que el mundo tiene que seguir su ejemplo, señala Kribbe, corre el riesgo de cometer el mismo error. Si no puede salvar al planeta del caos y el autoritarismo, debería esforzarse al menos por salvarse a sí misma, sin esperar a "su propio siglo de humillación para descubrir que sólo los fuertes pueden ser libres”.

${ }^{3}$ Aquella China era, en la feliz expresión de Alain Peyrefitte, "el imperio inmóvil" (L'Empire immobile ou Le Choc des mondes, Fayard, París, 1989). 